\title{
DESIGN AND FABRICATION OF LOW T/W RATIO AND HIGH PAYLOAD FRACTION MINI UAV
}

\author{
Abhishek R H ${ }^{1}$,Arundhati V P ${ }^{2}$, Anil K Nakkala ${ }^{3}$,Jadhav Darshan D ${ }^{4}$,Aditya $\mathrm{Y}^{5}$ \\ ${ }^{3}$ Assistant Professor, ${ }^{1,2,4,5}$ Students, Department of Aeronautical Engineering, KLS- Gogte Institute of Technology, \\ Belagavi, Karnataka, India-590006.
}

\begin{abstract}
This paper adresses the detailed overview and challenges facing while designing a low thrust to weight ration and high payload fraction unmanned aerial vehicles from the flight stability perspective. The main focus is to get sufficient pitch stiffness without using any external controllers in the process of achieving high payload fraction. Several Iterations are illustrated with different aerofoils like Eppler, NACA and S1223 to achieve required pitch stiffness. This paper also presents the longitudinal stability analysis and theoretical lateral and directional stability and control derivatives of the Mini UAV.
\end{abstract}

Keywords - Mini UAV, XFLR5, Pitch Stiffness, Stability derivatives.

\section{INTRODUCTION}

An aircraft with a high thrust to weight ratio has high acceleration. In most flight conditions, the aircrafts with a high thrust to weight ratio will also have an excess amount of thrust. High excess thrust results in a high rate of climb. If the thrust to weight ratio is greater than one and the drag is small, the aircraft can accelerate straight up like a rocket.

But it doesn't mean that an aircraft can't takeoff/fly with a thrust to weight ratio of less than one. Most of the commercial aircrafts have a thrust to weight of less than one. an aircraft with low thrust to weight ratio comes with benefits such as, reduced empty weight of the aircraft, maximum efficiency, reduction in the cost of propulsion system of the aircraft. We are presenting this paper with an aim to design and fabrication of an RC aircraft with low thrust to weight ratio as well as with high payload carrying capability.

\section{Design Methodology}

\section{A. Conceptual Design -}

Wing loading:

Wing loading is the total weight of an aircraft divided by the area of its wing. The value of wing loading was selected to be in between that of a glider and a trainer.

Wing configuration:
We had three options for choosing the wing configuration that is High wing, mid wing and Low wing. Going for a low wing would be not optimistic since our RC design doesn't have landing gears and choosing a mid wing would lead to manufacturing difficulties and would also consume the space available for the placement of payload, therefore a high wing configuration was chosen, also considering the stability the high wing configuration is Much stable compared to other configurations.

Tail configuration:

Conventional tail configuration was chosen in our design due to its high strength and manufacturing advantages.

Other options such as t-tail, h-tail, v-tail, was not chosen due to their less Strength (t-tail).

Airfoil selection:

Various airfoils such as e234, s1223 were analyzed using xflr , the selection was made based on the best,

\section{Aerodynamic efficiency that is $\mathrm{Cl} / \mathrm{cd}$}

2. $\mathrm{C}_{1} \max$

3. $\mathrm{C}_{\mathrm{d}}$

4. $\mathrm{C}_{\mathrm{m}}$ about aerodynamic chord

The first thing that designing entailed was the selection of an airfoil as it is the primary means to Generating sufficient lift and minimizing drag effects. After an extensive study, Selig S1223 was selected as the airfoil for the aircraft:

- s1223: for Wing

- naca001234: for tail

\section{XFLR ANALYSIS OF AIRFOIL:}

1. NACA001234 (green line) 
International Journal of Engineering Applied Sciences and Technology, 2020

Vol. 5, Issue 1, ISSN No. 2455-2143, Pages 600-605

Published Online May 2020 in IJEAST (http://www.ijeast.com)
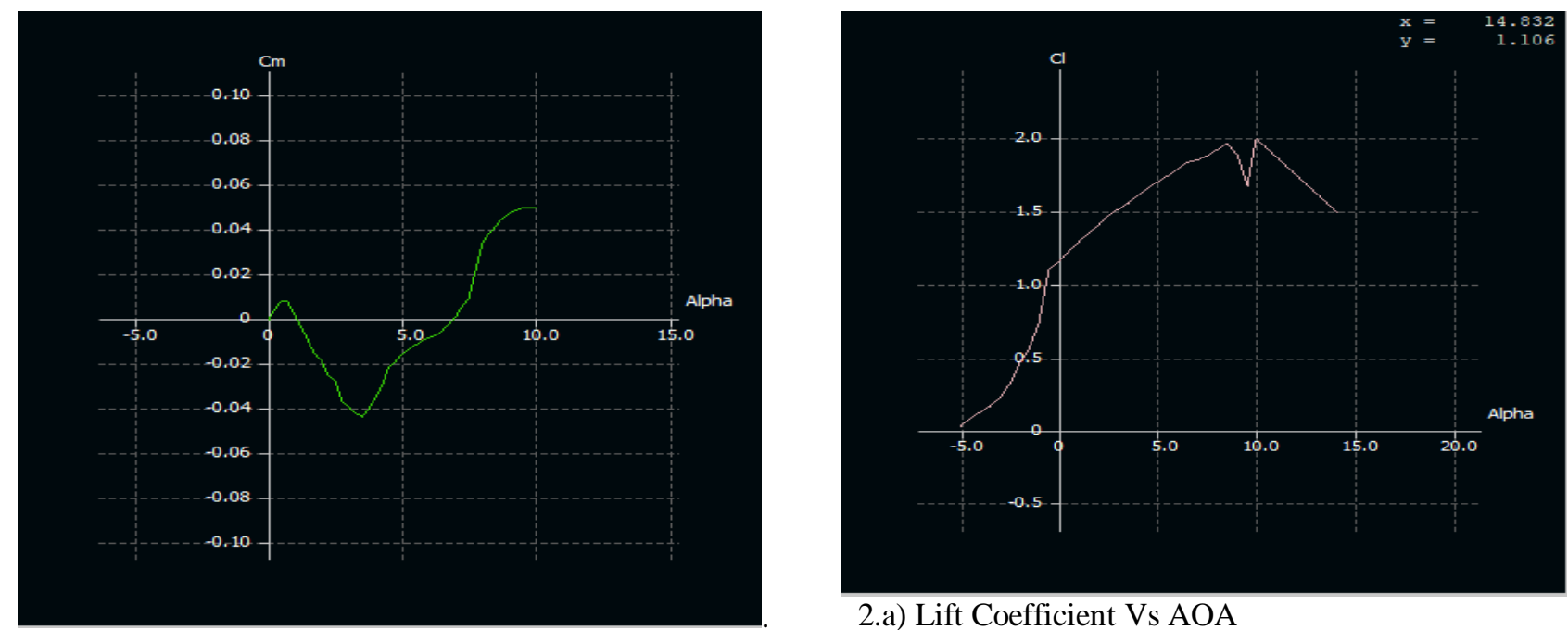

2.a) Lift Coefficient Vs AOA

a)Pitching Moment Vs Angle of Attack curve

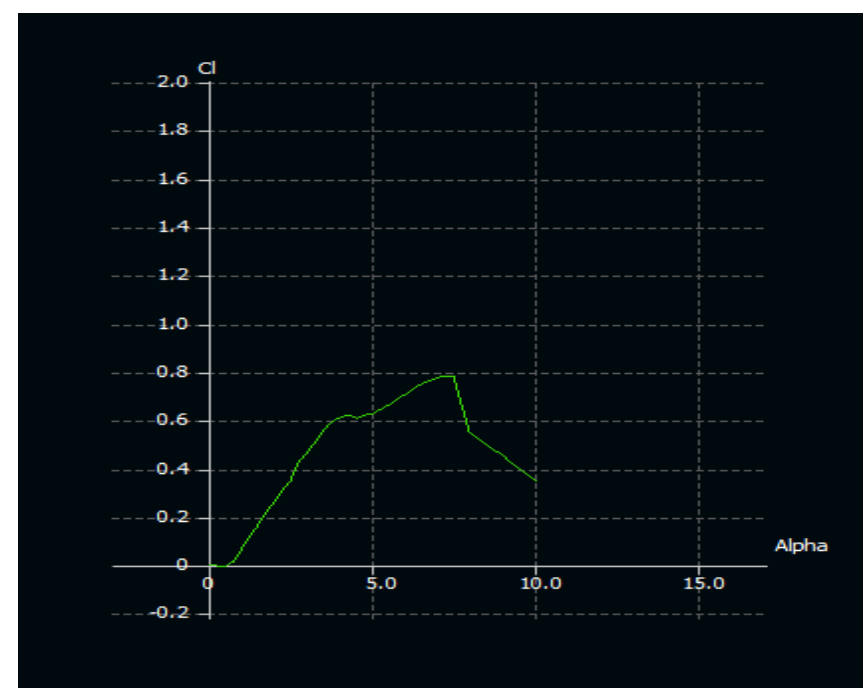

b) Lift Coefficient Vs AOA

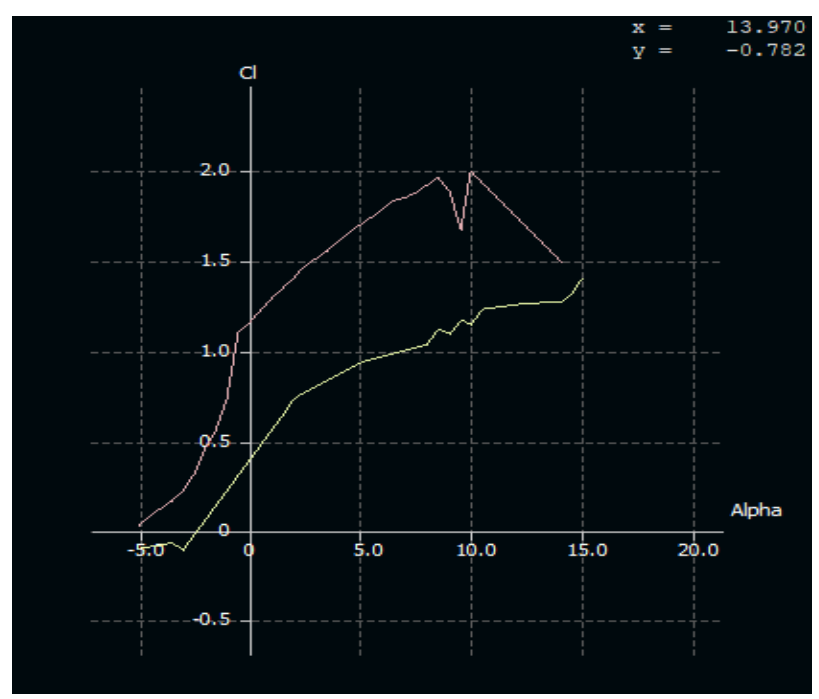

2. b) Comparison Of Lift Coefficient

2. S1223(pink line) and E423(yellow line):

Comparison of Eppler and S1223 aerofoils are give below. Fig 2.b represents the comparison of lift coefficient with respect to angle of attack and Fig 2.c gives the aerodynamic efficiency variation along with angle of attack.

From these Preliminary observations it is concluded that S1223 aerofoil is satisfying the required characteristics to design a high payload fraction low thrust to weight ratio unmanned aerial vehicle.

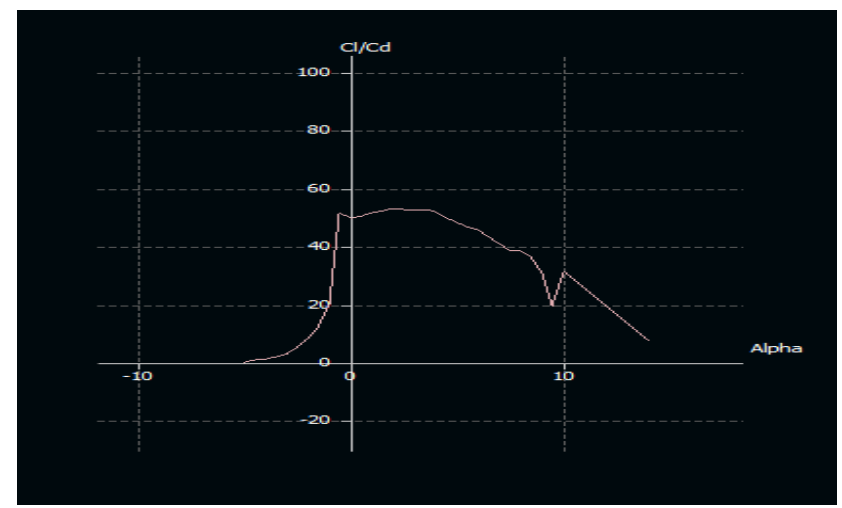

2. c) S1223 aerofoil Aerodynamic Efficiency curve 
International Journal of Engineering Applied Sciences and Technology, 2020

Vol. 5, Issue 1, ISSN No. 2455-2143, Pages 600-605

Published Online May 2020 in IJEAST (http://www.ijeast.com)

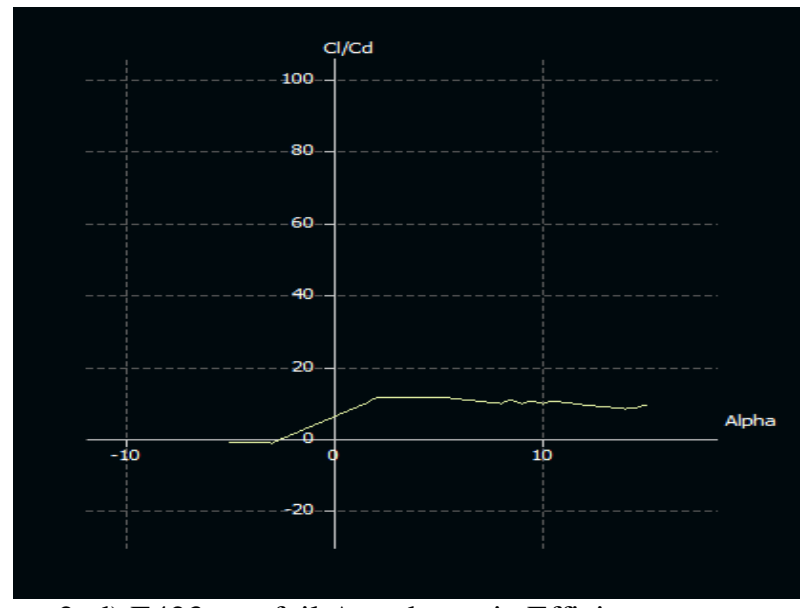

2. d) E423 aerofoil Aerodynamic Efficiency curve

\section{B. Actual Design}

Based on the below shown formulae the aircraft was designed, although the design was finalized after performing stability analysis on xflr5 software.

Standard relations as per stability:

- Wing span (b_w) $=\sqrt{ }(\mathrm{ARw} *$ Swing)

- Wing chord (C_w) = Swing / bw (for rectangular wing)

- $\mathrm{St}=0.25^{*} \mathrm{Sw}$

- Tail span (bt) $=\sqrt{ } \mathrm{ARt} * \mathrm{St}$

$\bullet \Lambda=0.45$

- Tail root Chord C_root $=2 \mathrm{St} / \mathrm{bt}(1+\lambda \mathrm{t})$

- Tail tip chord C_tip $=\lambda \mathrm{t} * \mathrm{C}_{\text {root }}$

- Fuselage length $=4 \mathrm{C}_{-} \mathrm{w}$

The specifications of the model are: -

\begin{tabular}{|c|c|}
\hline $\begin{array}{c}\text { Wing loading without } \\
\text { payload }\left(\mathrm{g} / \mathrm{cm}^{\wedge} 3\right.\end{array}$ & 0.381 \\
\hline Chord & $16 \mathrm{~cm}$ \\
\hline Wing area & $1696 \mathrm{~cm}^{2}$ \\
\hline Aspect Ratio & 6.625 \\
\hline Tail area & $307 \mathrm{~cm}^{2}$ \\
\hline Tail span & $41.2 \mathrm{~cm}$ \\
\hline Root chord & $10.3 \mathrm{~cm}$ \\
\hline Tip chord & $4.6 \mathrm{~cm}$ \\
\hline Rudder height & $16.48 \mathrm{~cm}$ \\
\hline Fuselage length & $64 \mathrm{~cm}$ \\
\hline
\end{tabular}

Electronics used:

\begin{tabular}{|c|c|}
\hline Motor & $\begin{array}{c}\text { Racer star BR2826 } \\
1290 \mathrm{KV} 2-4 \mathrm{~S}\end{array}$ \\
\hline Servo & sg90 \\
\hline Transmitter/receiver & $\begin{array}{c}\text { Fly Sky FS-i6 2.4G 6CH } \\
\text { PPM RC transmitter with FS- } \\
\text { iA6B receiver }\end{array}$ \\
\hline Esc & $30 \mathrm{~A}$ \\
\hline
\end{tabular}

- Glide test was carried out on the model to check the lift as well as to rectify any possible Correction to be made in the model; based on which Control surfaces have been properly trimmed as per requirement to ensure roll and yaw stability.

- The no of channels required were five so, a Fly Sky FS-i6 2.4G 6CH PPM RC transmitter withFS-iA6B receiver is being used to control the aircraft.

- Motor was roughly chosen based on the gross thrust to weight ratio, later thrust was reduced to the minimum value, from the motor the net current required by the aircraft was determined, based on which a $30 \mathrm{amp}$ electronic speed controller Chosen. $\mathrm{Sg} 90$ servos were used to operate the control surfaces during the entire flight. The motor is coupled with a 1045 propeller to get the required thrust output.

- Neutral point is at $121 \mathrm{~mm}$ and the pitch stiffness is 1.2999 /radian

Stability analysis was executed with the payload placed at the desired locations as shown in theFigure 2.e below

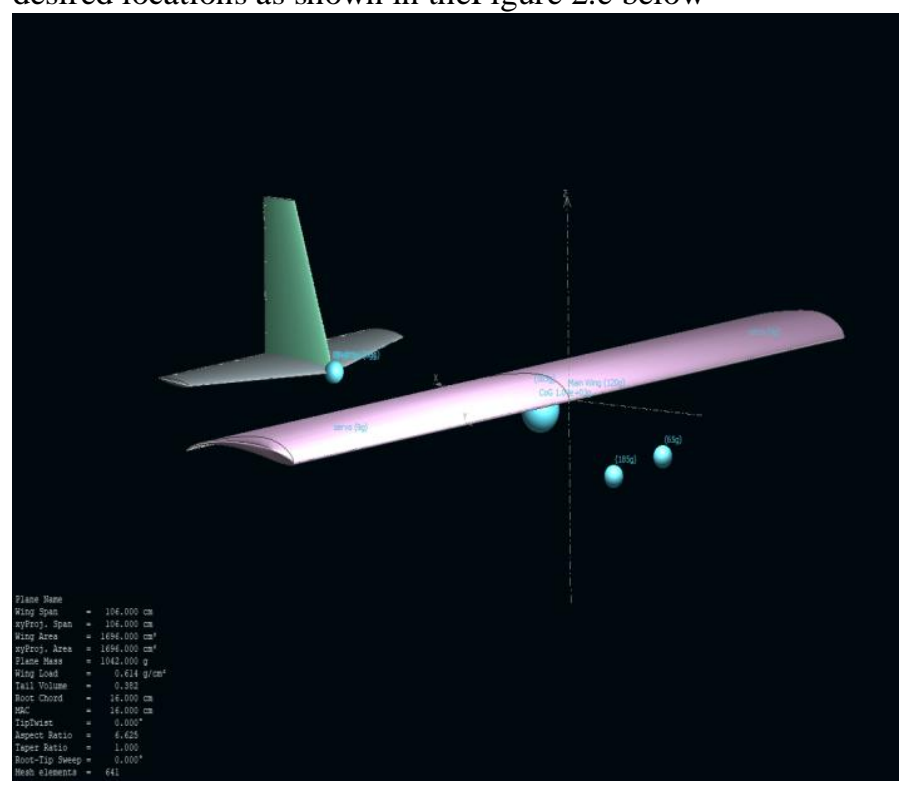

2.(e) Stability analysis of UAV in XFLR5 


\section{International Journal of Engineering Applied Sciences and Technology, 2020 Vol. 5, Issue 1, ISSN No. 2455-2143, Pages 600-605 \\ Published Online May 2020 in IJEAST (http://www.ijeast.com)}

\section{FABRICATION}

To go forward with the fabrication, the SOLIDWORKS model is made where all the weight Contraints are estimated. Particularly balsa Wood is used for maximum payload fraction. Then each Part dxf software 2D diagram is taken for the laser cutting.later attached each components with glues.

\section{A) Solid works model}

A preliminary solid works model was designed as shown in fig 3.(a) to get a rough weight approximation, and also further design tweaks which had to be done to optimize the space inside the fuselage were made.

\section{B) Fabrication}

\section{WING}

- For wing construction, only ribs with desired airfoil shape are cut. Rectangular and circular holes are Made in the ribs for spars.

- $\quad$ There are 3 spars used. To make the wing stiffer and to make it Capable of lifting the loads of the aircraft, one of the spars used is a carbon fiber rod.

- Carbon fiber Rod was chosen due to its high strength to weight ratio.

- Rib spacing was determined based on span of the wing, mid wing portion was especially made with thick airfoils $(6 \mathrm{~mm})$ to make the structure more rigid. after the placing the ribs and spa rat required positions the wing was covered with monokote(red) which was glued to the ribs using a iron box.

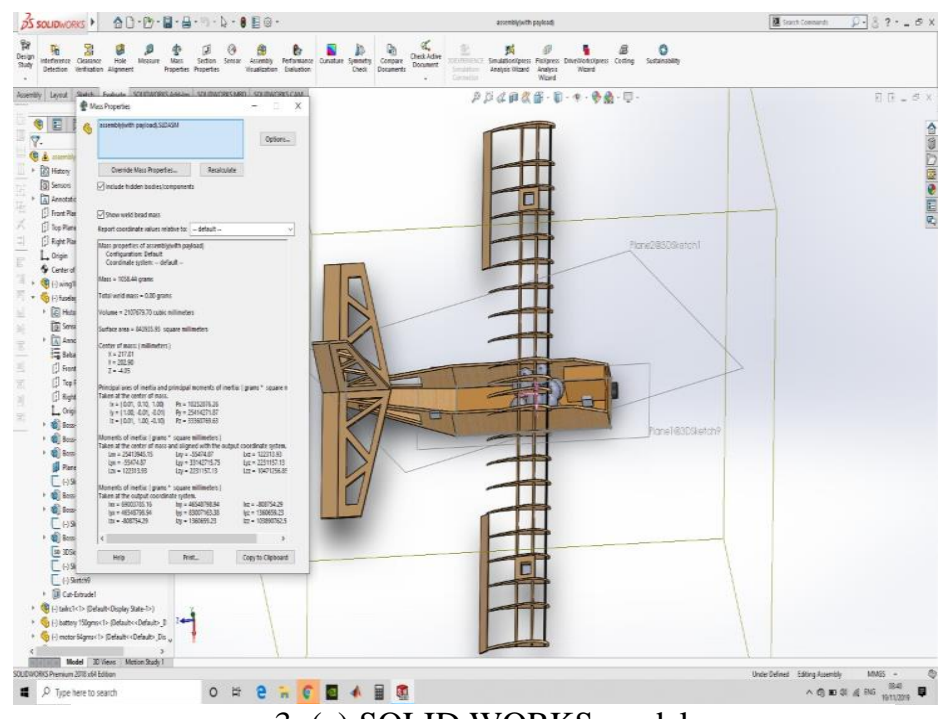

3. (a) SOLID WORKS model

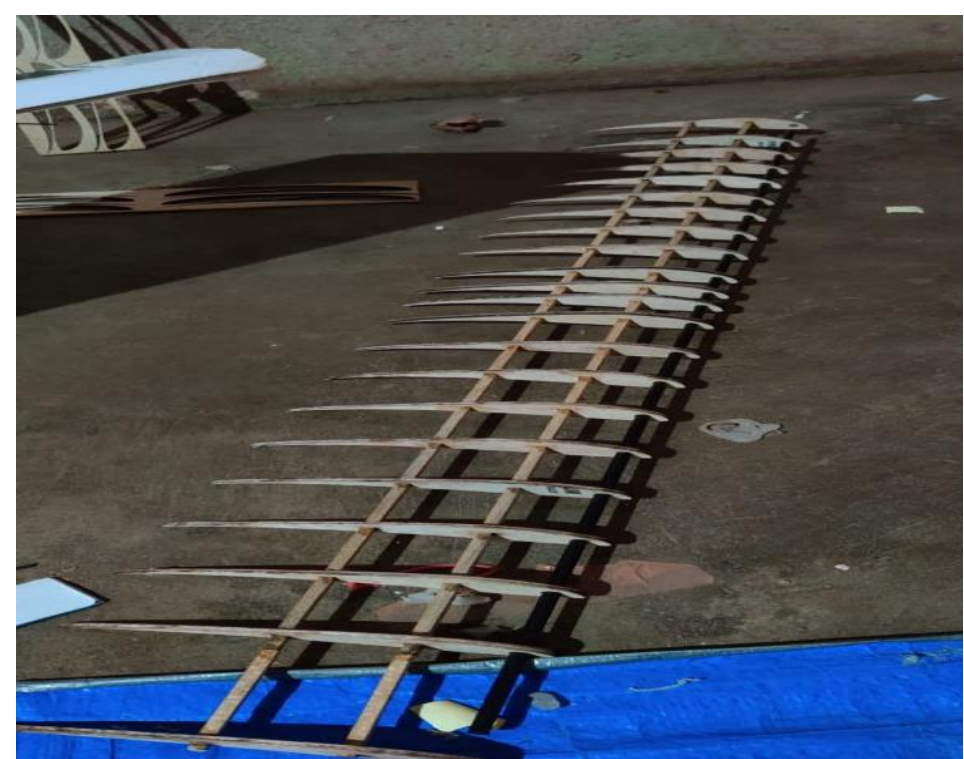

\section{CONTROL SURFACES}

3.(b) Wing Fabrication

The control surfaces were designed using the standard relations as per stability, and were cut from balsa wood.

Servo motors were utilized for the actuation of these control surfaces. For coupling servo motor and control surfaces pushrods, control linkage and control horns have been used.

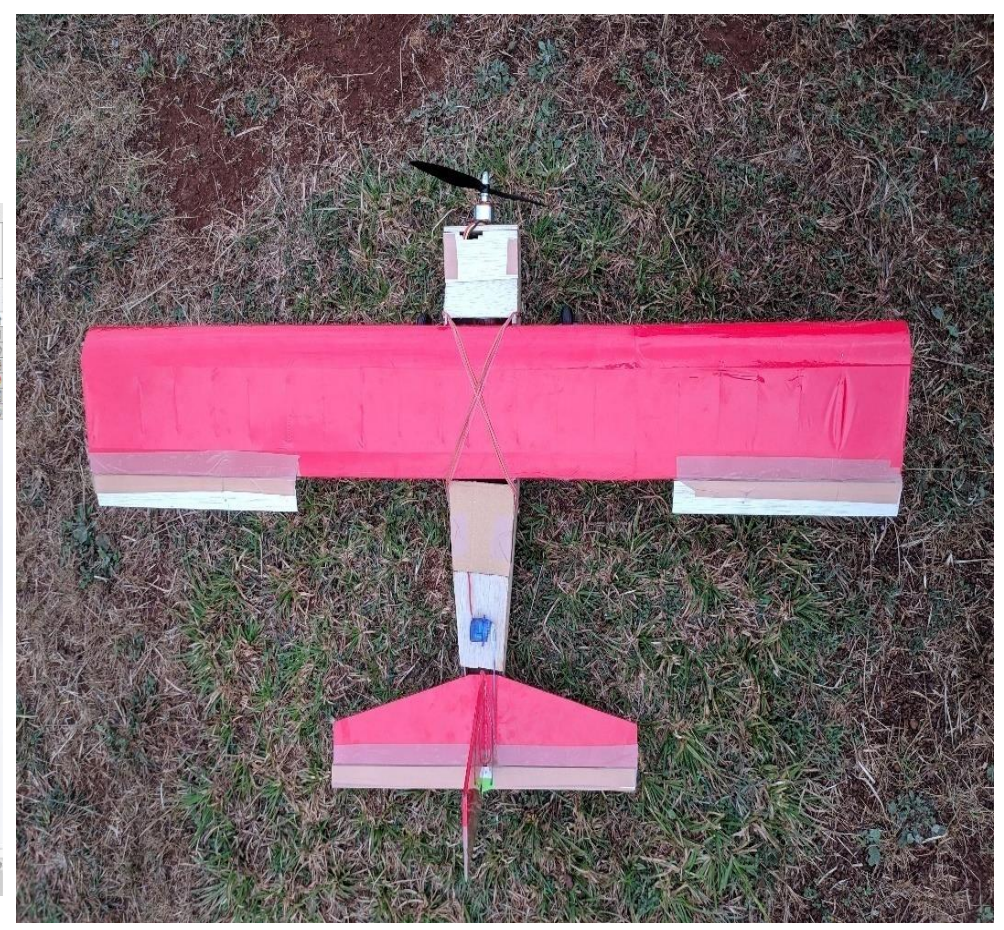

3. (c) Final Model 


\section{RESULT}

After Successful flight testing the following results were obtained,

Table -1 Experiment Result

\begin{tabular}{|c|c|c|c|}
\hline T/W & $\begin{array}{c}\text { EMPTY } \\
\text { WEIGHT }\end{array}$ & PAYLOAD & $\begin{array}{c}\text { PAYLOAD } \\
\text { FRACTION }\end{array}$ \\
\hline 0.4 & $742 \mathrm{~g}$ & $630 \mathrm{~g}$ & 0.849 \\
\hline
\end{tabular}

Table 1 addresses the total payload fraction is 0.849 with thrust to weight ratio is 0.4 .

\section{CONCLUSION}

Design and fabrication of the RC aircraft has been successfully carried out, with the desired stability criteria and minimum thrust to weight ratio of 0.4 has been achieved.

\section{ACKNOWLEDGMENTS}

The Authors would like to thank Gogte Institute of technology for the financial support provided to them for this project.

\section{REFERENCE}

[1] Daniel P. Raymer "Aircraft design: A Conceptual Approach",. AIAA Education Series; Chap 4.

[2] Nelson, R.C (1998). "Flight stability and automatic control", McGraw Hill 2ndEdition.

[3] Hemant Sharma, C. S. Suraj, Roshan Antony, G. Ramesh, Sajeer Ahmed and Prasobh Narayan "Design of a High Altitude Fixed Wing Mini UAV - Aerodynami Challenges", ICIUS-2013-129

[4] Saifur Rahman Bakaul, Md. Abdus Salam, FairusSakib Tanzim, Abdullah Al Faysal, Md. Shafique, Kh. Md. Faisal, Design and fabrication of a micro-class unmanned aerial vehicle (UAV) with high payload fraction, IOSR Journal of Mechanical and Civil Engineering, e-ISSN: 2278-1684,p-ISSN: 2320-334X, Volume 7, Issue 5 (Jul. Aug. 2013), PP 36-46

[5] Anderson, Jr. J.D. "Introduction to flight" McGraw Hill 2005.

[6] Etkin, B. and Reid L.D. "Dynamics of Flight-Stability and Control" 3rdEdition, John Wiley 1996

[7] Pamadi, B. "Performance, stability, dynamics and control of airplanes",2ndEditionAIAA 2004.
[8] Phillips , W.R. "Mechanics of flight "2ndEditionJohn Wiley 2010

[9] McCormick, B.W. "Aerodynamics, aeronautics and flight mechanics", JohnWiley 1995.

[10] Phillips , W.R. "Mechanics of flight "2ndEditionJohn Wiley2010.

[11] Anderson, J.D., "Fundamental of Aerodynamics", 3rdEdition, McGraw-Hill Series in Aeronautical and Aerospace Engineering, NY, 2001.

[12] aisuke Sasaki, Astushi Ito, Takashi Ishida and Kazuhiro Nakahashi, '27thAIAA Applied Aerodynamics Conference 22-25 June 2009, San Antonio, Texas

[13] Tulapurkara E.G.et al., "An Example of Airplane Preliminary Design Procedure - Jet Transport", Report No. AE-TR- 2007-4, IIT Madras, 2007.

[14] HaiYang Chao, YongCan Cao and YangQuan Chen, Autopilots for Small Unmanned Aerial Vehicles: A Survey, International Journal of Control, Automation, and Systems, 8(1), 2010, 36-44. 